\title{
Systemic Lupus Erythematosus Nephritis Class II
}

National Cancer Institute

\section{Source}

National Cancer Institute. Systemic Lupus Erythematosus Nephritis Class II. NCI

Thesaurus. Code C123116.

Systemic lupus erythematosus nephritis exhibiting mesangial hypercellularity or mesangial expansion by light microscopy, with mesangial immune deposits. Isolated subepithelial or subendothelial deposits may be visible by immunofluorescence or electron microscopy, but not by light microscopy. (Weening, Jan J. et al. (2004). The Classification of Glomerulonephritis in Systemic Lupus Erythematosus Revisited. Journal of the American Society of Nephrology 15(2), 241-50.) 